\title{
Queueing Network Modeling and Lead Time Compression of Electronic Procurement
}

\author{
C.V.L. Raju , Y. Narahari
}

\begin{abstract}
Procurement, i.e., the process of obtaining materials or services and managing their inflow into organizations, is a critical process in supply chain management. Internet technologies offer attractive opportunities to reduce purchasing costs while increasing the speed and efficiency of the procurement process through seamless network integration and automated execution of key tasks. This paper attempts to model e-procurement from a lead time perspective, to capture the effects of Internet technologies on the procurement lead time. The model we develop is a multiclass queueing network called a probabilistic reentrant line. The model captures several important facets of an eprocurement process, such as use of electronic RFQ (request for quotation) in systematic sourcing, use of Internet auctions in spot purchasing, contention for procurement resources, randomness in execution times of procurement tasks, and concurrent execution of multiple procurement activities. The analysis of the queueing model suggests that end-to-end lead times in eprocurement can be compressed in ingenious ways using standard queueing theoretic techniques.
\end{abstract}

Keywords: Procurement process, mean cycle time, eprocurement, multiclass queueing networks, re-entrant line.

\section{INTRODUCTION}

GLECTRONIC procurement is one of the newer Fand more impressive solutions that have emerged within the $\mathrm{B} 2 \mathrm{~B}$ e-commerce space. Internet and $\mathrm{e}$ commerce technologies, such as electronic catalogs, electronic mail, search engines, electronic requests for quotation (RFQ), and electronic data interchange (EDI) are dramatically changing the purchasing process. They are altering the methods, purposes, and results of the procurement function. e-procurement is transforming the way companies communicate requirements and find the right sources for goods and services. Web-based procurement allows companies to establish electronic links between users and suppliers. Business rules, such as preferred suppliers, pricing, budgets, and approval levels are established and communicated to internal users. Remote users can access this information to get the non-production goods and services they need. The result is lower total costs and increased pro-

Department of Computer Science and Automation, Indian Institute of Science, Bangalore-560012, India

Department of Computer Science and Automation, Indian Institute of Science, Bangalore-560012, India ductivity.

\section{A. Relevant Work}

Benefits of e-catalogs and their use in web-based B2B procurement systems are studied by Baron et al. [13]. Intensive field study has been done on Internet purchasing practices by Segev, Beam, and Gebauer [1] and they summarize conclusions on many issues of e-procurement processes. Gebauer and Faerber [2] have reported a comprehensive case study on how the Lawrence Livermore National Laboratory (LLNL) has utilized emerging technologies to support engineering and procurement processes. Some key principles for integrating intelligent agent technology into procurement processes are given by Nissen[3]. Information about procurement processes in various industries, is available from sources like Center for Advanced Purchasing Studies Research [7], and PurchsingNet [8].

Modeling of business processes using queueing networks to explore cycle time reduction strategies is the subject of [9], [14]. In [9], the authors model a product design and development organization at a fairly high level of abstraction using probabilistic re-entrant lines. It is shown how lead time reduction strategies such as input control, load balancing, efficient scheduling, and variability reduction can be put to work using the queueing network model. The paper argues the usefulness of fluctuation smoothing scheduling policies in the context of real-world product development organizations. In [14], a novel application of applying multiclass queueing network models to suggest lead time compression strategies in pharmaceutical drug discovery and development process is described. The authors of [14] use probabilistic re-entrant lines as the model and show that such a model can capture the project dynamics in drug development organizations that involve multiple, concurrent projects with contention for human/technical resources. The authors explore how drug development lead times can be reduced using efficient scheduling and critical mass-based resource management.

\section{B. Contributions and Outline}

In this paper, our objective is to model the eprocurement process from a lead time perspective, to capture the effects of Internet technologies on the procurement lead time. The model we develop is a multi- 
class queueing network called a probabilistic reentrant line. The model captures several important facets of an e-procurement process, such as use of electronic request for quotation in systematic sourcing, use of Internet auctions in spot purchasing, contention for procurement resources, randomness in execution times of procurement tasks, and concurrent execution of multiple procurement activities. The analysis of the queueing model reveals several opportunities for compression of end-to-end lead times in e-procurement.

In Section 2, we describe the activities and workflow in a generic procurement process. The flow model we present captures all important decisions and players in the procurement process. In Section 3, we develop a reentrant line model for a typical e-procurement process. The model is quite conceptual and serves to describe aggregately the flow of procurement work elements in any e-procurement process. The modeling of certain situations in the e-procurement process calls for use of intricate queueing principles and we describe one such modeling construct, called the Centralized Splitting Model, in the remainder of Section 3. Section 4 is devoted to performance analysis of the re-entrant line model. We also bring out the implications of the results obtained.

\section{A Generic Procurement Process}

Figure 1 illustrates the flow of information in a generic e-procurement process. The procurement process begins with a user (buyer) in the organization identifying a need (a set of items to be procured) and determining preliminary purchasing requirements. The user browses e-catalogs which are provided by suppliers with whom long-term relationships have already been established (systematic sourcing) and loaded on to an e-procurement software tool. If the user finds the items in the existing list of e-catalogs, he follows one of the following sequences of activities, (a) check inventory-fulfill order-update database, (b) check inventory-initiate purchase order.

If the items are not in the existing e-catalogs, the user sends a request letter to technical release representatives (TRRs), who act as an interface between users and the purchasing department and are delegated a specified level of procurement authorization. TRRs may suggest to the users some modifications to the purchasing order. After getting feedback from the user, TRRs recognize the level of purchasing, and they either send request for quotation (RFQ) to a private 1 or a public 1 (who provides value added services to both the buyer and seller), or send to the purchasing department (PD). After scrutinizing the purchasing request, purchasing department either rejects the request or prepares and sends RFQ to the e-marketplace.
In this model we assume, for the sake of simplicity, that there will not be any rejections at the purchasing department.

At the e-marketplace, vendors who are interested in supplying the items process the RFQ and may need to get some clarifications. If suppliers do not have any doubts about RFQ or are satisfied with the feedback given by TRRs or PD, they submit bids and the e-marketplace conducts a negotiation, possibly an eauction, and finds the winners among the bidders. We consider this process as spot sourcing since the vendors do not possibly have long-term relationship with the organization. After receiving the purchase order, suppliers (both systematic and spot sourcing) initiate shipping activity and the purchasing department initiates payment transaction.

\section{A QUEUEING NETWORK MODEL FOR E-PROCUREMENT}

From Figure 1, we can make the following three observations about a generic procurement process.

1. The procurement process has six major nodes, (1) User (i.e. buyer), (2) Technical Release Representative, (3) Purchasing 0, (4) e-marketplace, (5) Suppliers (systematic sourcing), and (6) Suppliers (spot sourcing). Each node contains a set of tasks to be carried out.

2. In a generic procurement process, a typical procurement transaction visits the same node several times, at different stages of processing, before exiting the system, thus making the flow re-entrant. This is the primary motivation for using re-entrant lines to model the procurement process.

3. When the buyer seeks bids from the suppliers, it may be for a bundle of materials. In response to the RFQ, the suppliers concurrently send the bids for the entire bundle or parts of the bundle. Typically, the buyer will wait for responses from all the suppliers before selecting the vendors from whom to purchase. The buyer may send purchase orders to a subset of the suppliers. The selected vendors ship the materials and at the buyer end, the buyer will have to wait until all the materials shipped by all the vendors are received.

Based on the above observations, we develop a queueing network model to capture the decisions and dynamic flow of tasks within a generic e-procurement process. The model we develop is a probabilistic reentrant line.

\section{A. A Re-entrant model for e-procurement process}

In a re-entrant line, the jobs visit the same server several times, at different stages of processing, before exiting the system, thus making the flow re-entrant. A re-entrant line can be described as follows. There is set of service centers $\{1,2, \ldots, m\}$. Service center 


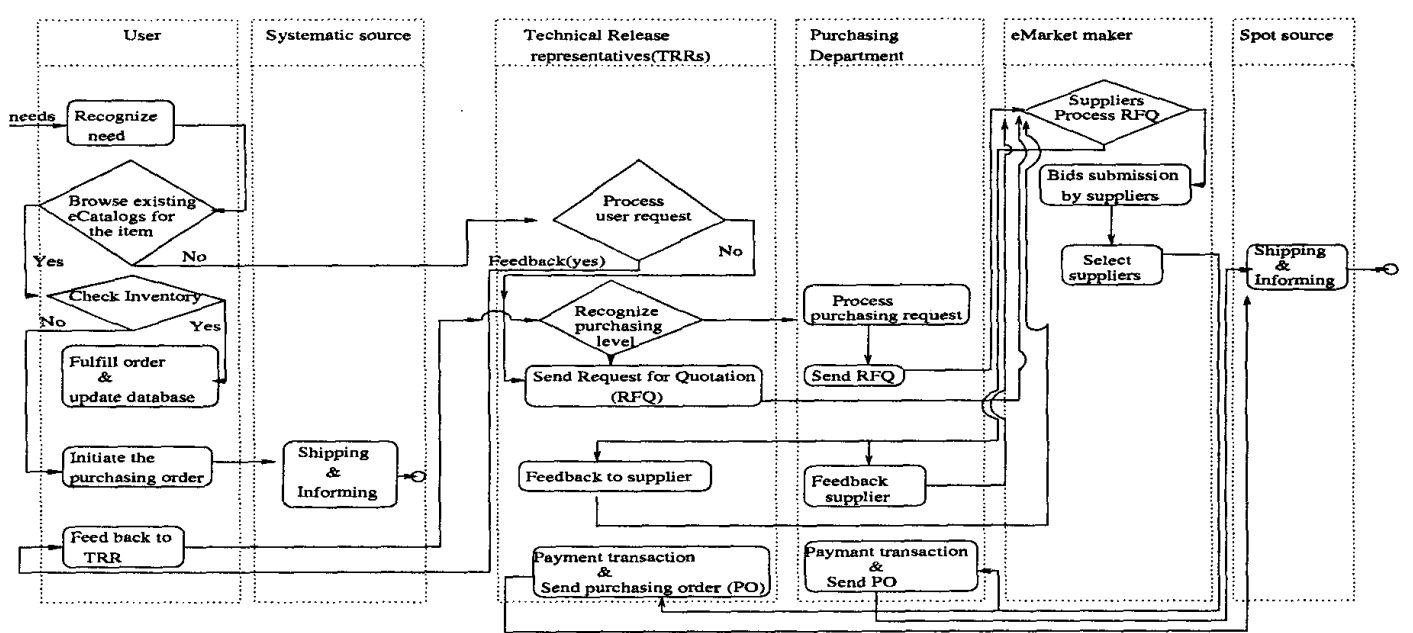

Fig. 1. Process flow diagram for a general e-procurement process

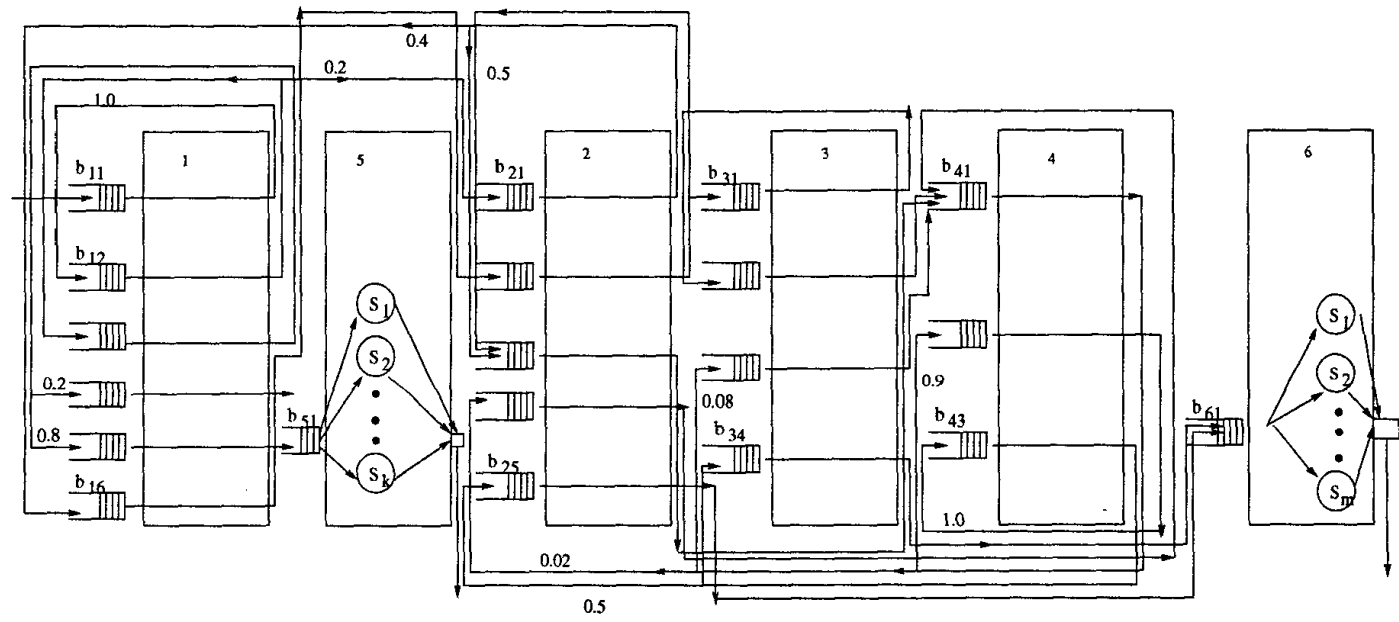

Fig. 2. re-entrant line queueing network model for e-procurement process

$i \in\{1,2, \ldots, m\}$ has $n_{i}$ logical or physical buffers, $b_{i 1}, b_{i 2}, \ldots, b_{i n_{i}}$. For $j \in\left\{1,2, \ldots, n_{i}\right\}$, the buffer $b_{i j}$ contains parts visiting service center $i$ for the $j^{\text {th }}$ stage of processing. A part visits these buffers in a given sequence and any service center is typically visited several times in the route of a part.

The re-entrant line [5] model in Figure 2 contains 6 stations and 20 buffers. The multiple buffers at a given station contain procurement transactions, which are revisiting the station after having completing processing at various other stations. For example station 1 contains 6 buffers, $b_{11}, \ldots, b_{16} . b_{11}$ contains PTs which are visiting this node for the first time. $b_{16}$ contains PTs which are visiting the station for rework after having undergone an operation or rework at sta- tion 2. Likewise we can describe the PTs in the other buffers also. The processing time distributions could be different for procurement transactions in different buffers. Details of service times (we take aggregated values, since we model the procurement process to certain level of aggregation) are given in Table 1.

The scheduling problem in a re-entrant line becomes interesting because several PTs at different stages of processing may be in contention with one another for service at the same service center. Several researchers have studied the issue of scheduling in reentrant line [5], [6]. Distributed scheduling policies based on buffer priorities and due dates have been formulated and investigated by Kumar [5], and Lu, Deepa, and Kumar [6]. Kumar [5] has investigated, 
among others, the following fixed buffer priority policies: FBFS (First Buffer First Serve) and LBFS (Last Buffer First Serve). In a buffer priority policy, the buffers are assigned different static priorities. After finishing the service on a PT, the service center will pick up a PT from the buffer having the highest priority (if one is available, of course). For example, in the case of LBFS, we order the $n_{i}$ buffers of processing center $i$ as $b_{i n_{i}}, b_{i\left(n_{i}-1\right)}, \ldots, b_{i 2}, b_{i 1}$ in decreasing order of priority. The next PT selected for processing is the one that has finished most of its processing, and hence one with the least amount of processing remaining. Thus we may say that each processing center myopically tries to clear PTs from the system as fast as possible. Other popular policies are due-date based policies such as EDD (Earliest Due Date first) and LS (Least Slack first). Fluctuation smoothing policies [6] are a special class of Least Slack scheduling policies [5]. See [6] for a good overview of fluctuation smoothing policies. We will look at three such fluctuation smoothing policies: fluctuation smoothing policy for variance of lateness (FSVL), fluctuation smoothing policy for variance of cycle time (FSVCT), and fluctuation smoothing policy for mean cycle time (FSMCT).

There are two nodes in the above re-entrant model which need special attention. The first one corresponds to the process of suppliers sending their bids to the buyer. The second one corresponds to the process of the suppliers shipping different parts of a bundle of requirements to the buyer. In either case, the buyer needs to wait to receive the information or materials from all the selected suppliers before the next task in the procurement process can be initiated. We have modeled these two nodes in an accurate way, using a queueing extension called Centralized Splitting (CQ/S) proposed in [10].

B. $C Q / S$ model for concurrent execution of supplier tasks

We now describe the modeling of concurrent execution of supplier tasks depicted in two spots in Figure 2. In this $\mathrm{CQ} / \mathrm{S}$ model, we consider the arrivals at the queue are individual items. The items that arrive form a group of procurement transaction (lots to be purchased). So the underling parallel processing system of interest is $M^{x} / M / c$ queue [10]. The aggregated mean response time for the $\mathrm{CQ} / \mathrm{S}$ model is given by Nelson et al [10]. In this model the number of suppliers for systematic and spot purchasings are $k$ and $m$, respectively. We assume that at any given time there are a fixed number of spot and systematic suppliers. We assume that procurement processes are scheduled into service in first-come first-serve manner. Items in a single procurement transaction are scheduled in random order. The following is a brief outline of the analy- sis of CQ/S system, as developed in [10]. For details of analysis refer [11], [10]. Consider a CQ/S queueing system with $c$ suppliers, who do the shipping and informing of different items. The time required for the shipping and informing an item is assumed to be an exponential random variable with parameter $\mu$ and is independent of the time requirements of all other tasks. The procurement transaction is considered to have been completed only when all the items with that purchase order have been fulfilled.

The number of items in a procurement transaction is a random variable, which has probability distribution $\alpha_{i}=\mathrm{P}[\mathrm{X}=\mathrm{i}], \mathrm{i}=1,2, \ldots$, and probability generating function,

$$
X(z)=\sum_{i=1}^{\infty} \alpha_{i} z^{i}
$$

the mean response time $\mathrm{T}$ of a procurement transaction at shipping and informing activity is the sum of the mean waiting time $\mathrm{W}$, which is the procurement transaction waiting time and corresponds to the time that the procurement transaction waits in the queue before the first of its items is shipped, and the mean service time $S$, is the procurement transaction service time and corresponds to the time required to process all of the items associated with the procurement transaction once the first item is shipped.

$$
T=W+S
$$

In this paper we consider a special case where the number of items in a procurement order is a geometric random variable.

$$
P[X=n]=p^{n-1}(1-p), n>0
$$

Refer [10] for finding the procedure to compute approximate values for $\mathrm{W}$ and $\mathrm{S}$. By using the mean response time $\mathrm{T}$ for shipping and informing activity, we can replace suppliers (both systematic and spot sourcing) $s_{1}, s_{2}, \ldots, s_{i}$ by a single aggregated supplier who takes time $\mathrm{T}$ for shipping and informing activity.

\section{RESUlts AND CONClusions}

\section{Numerical Results and IMPlications}

For experimenting with the re-entrant model, we have created a hypothetical e-procurement organization, based on inputs from several purchasing managers. The numerical results are obtained by a detailed simulation using a re-entrant line simulation package called RLSIM developed at the e-Enterprises Laboratory, Department of Computer Science and Automation, Indian Institute of Science. Each simulation is run to complete about 4000 purchasing needs, and 
TABLE I

MEAN SERVICE TIMES FOR THE QN MODEL OF THE E-PROCUREMENT PROCESS

\begin{tabular}{cccccc}
\hline \hline $\begin{array}{c}\text { Station } \\
\text { Mean service }\end{array}$ & 1.1 & 1.2 & 1.3 & 1.4 & 1.5 \\
time (hours) & 0.5 & 0.25 .0 & 0.2 & 0.5 & 0.5 \\
$\begin{array}{c}\text { Station } \\
\text { Mean service }\end{array}$ & 1.6 & 2.1 & 2.2 & 2.3 & 2.4 \\
time (hours) & 4 & 2.0 & 1.0 & 0.5 & 6 \\
$\begin{array}{c}\text { Station } \\
\text { Mean service } \\
\text { time (hours) }\end{array}$ & 2.5 & 3.1 & 3.2 & 3.3 & 3.4 \\
$\begin{array}{c}\text { Station } \\
\text { Mean service }\end{array}$ & 4.1 & 4.2 & 4.3 & 5.1 & 6.1 \\
time (hours) & 1.5 & 1 & 1.5 & 24 & 72 \\
\hline
\end{tabular}

TABLE II

MEAN AND VARIANCE OF END-TO-END PROCUREMENT LEAD TIME

\begin{tabular}{lll}
\hline $\begin{array}{l}\text { Inter arrival } \\
\text { time in hours }\end{array}$ & $\begin{array}{l}\text { MPLT in } \\
\text { hours }\end{array}$ & VPLT \\
\hline & & \\
24 & 106 & 119.07 \\
25 & 100.5 & 123.672 \\
27 & 95.91 & 117.67 \\
28 & 84.372 & 104.88 \\
30 & 78 & 92.588 \\
32 & 75.05 & 101.26 \\
34 & 67.51 & 84.65 \\
36 & 66.11 & 84.701 \\
38 & 61.91 & 76.901 \\
40 & 60.58 & 81.445 \\
\hline \hline
\end{tabular}

the performance measures are computed after deleting an appropriate number of initial transients. In the simulation, arriving jobs are assigned due dates which are randomly drawn from a carefully chosen window. e-procurement process mean end-to-end procurement lead time (MPLT) and variance of end-to-end procurement lead times (VPLT) for different inter arrival times (IAT) (the time gap between two successive purchase needs) are given in Table 2. We observe lead time reduction by increasing IAT.

Table 3 shows the effect of scheduling of internal work in the e-procurement process. We look at four indices of performance: Mean end-to-end procurement lead time, Variance of end-to-end procurement lead time, Average lateness, and Variance of lateness. We consider various scheduling strategies: FCFS, FBFS, LBFS, FSMCT, FSVCT, and FSVL. Note that the FSMCT and LBFS policies are attractive for minimizing mean end-to-end procurement lead time (MPLT) while the FSVCT policy, as expected, minimizes the variance of end-to-end procurement lead time (VPLT). Applying fluctuation smoothing to improve lead time performance is a very attractive technique for lead
TABLE III

Performance of E-PRocurement UNDER FLUCTUATION SMOOTHING POLICIES

\begin{tabular}{|c|c|c|c|}
\hline & $\begin{array}{l}\text { IAT }= \\
24 \mathrm{hrs}\end{array}$ & $\begin{array}{l}\text { IAT }= \\
25 \text { hrs }\end{array}$ & $\begin{array}{l}\text { IAT }= \\
28 \mathrm{hrs}\end{array}$ \\
\hline \multicolumn{4}{|l|}{ FCFS Policy } \\
\hline $\begin{array}{l}\text { Mean PLT (hours) } \\
\text { Variance of PLT } \\
\text { Average Lateness } \\
\text { Variance of Lateness }\end{array}$ & $\begin{array}{l}106 \\
119.07 \\
-93.57 \\
209.88 \\
\end{array}$ & $\begin{array}{l}100.5 \\
123.672 \\
-90.18 \\
207.285 \\
\end{array}$ & $\begin{array}{c}84.372 \\
104.88 \\
-78.84 \\
176.68 \\
\end{array}$ \\
\hline \multicolumn{4}{|l|}{ FBFS Policy } \\
\hline $\begin{array}{l}\text { Mean PLT (hours) } \\
\text { Variance of PLT } \\
\text { Average Lateness } \\
\text { Variance of Lateness }\end{array}$ & $\begin{array}{l}100.986 \\
104.735 \\
-81.421 \\
187.654 \\
\end{array}$ & $\begin{array}{l}98.201 \\
127.108 \\
-62.03 \\
195.555 \\
\end{array}$ & $\begin{array}{l}87.758 \\
104.748 \\
-74.554 \\
175.178 \\
\end{array}$ \\
\hline \multicolumn{4}{|l|}{ LBFS Policy } \\
\hline $\begin{array}{l}\text { Mean PLT (hours) } \\
\text { Variance of PLT } \\
\text { Average Lateness } \\
\text { Variance of Lateness }\end{array}$ & $\begin{array}{l}113.175 \\
158.94 \\
-81.96 \\
230.233 \\
\end{array}$ & $\begin{array}{l}109.612 \\
173.536 \\
-126.22 \\
268.950 \\
\end{array}$ & $\begin{array}{l}85.26 \\
115.829 \\
-92.3615 \\
191.0 \\
\end{array}$ \\
\hline \multicolumn{4}{|l|}{ FSMCT Policy } \\
\hline $\begin{array}{l}\text { Mean PLT (hours) } \\
\text { Variance of PLT } \\
\text { Average Lateness } \\
\text { Variance of Lateness }\end{array}$ & $\begin{array}{l}89.442 \\
145.482 \\
-48.328 \\
198.04 \\
\end{array}$ & $\begin{array}{l}81.165 \\
124.658 \\
-26.879 \\
163.651 \\
\end{array}$ & $\begin{array}{l}64.951 \\
99.469 \\
-28.209 \\
135.469 \\
\end{array}$ \\
\hline \multicolumn{4}{|l|}{ FSVCT Policy } \\
\hline $\begin{array}{l}\text { Mean PLT (hours) } \\
\text { Variance of PLT } \\
\text { Average Lateness } \\
\text { Variance of Lateness }\end{array}$ & $\begin{array}{l}93.345 \\
88.265 \\
-119.331 \\
167.46 \\
\end{array}$ & $\begin{array}{l}95.580 \\
87.081 \\
-97.003 \\
155.911 \\
\end{array}$ & $\begin{array}{l}85.626 \\
84.546 \\
-134.265 \\
174.155 \\
\end{array}$ \\
\hline \multicolumn{4}{|l|}{ FSVL Policy } \\
\hline $\begin{array}{l}\text { Mean PLT (hours) } \\
\text { Variance of PLT } \\
\text { Average Lateness } \\
\text { Variance of Lateness }\end{array}$ & $\begin{array}{l}111.329 \\
143.774 \\
-100.998 \\
229.576\end{array}$ & $\begin{array}{l}102.39 \\
124.6727 \\
-67.587 \\
188.342\end{array}$ & $\begin{array}{l}84.076 \\
99.35 \\
-61.61 \\
155.735\end{array}$ \\
\hline
\end{tabular}

TABLE IV

LEAD TIME REDUCTION THROUGH INPUT CONTROL

\begin{tabular}{llll}
\hline \hline $\begin{array}{l}\text { Population of } \\
\text { closed model }\end{array}$ & $\begin{array}{l}\text { MPLT in } \\
\text { hours }\end{array}$ & $\begin{array}{l}\text { Associated } \\
\text { Mean IAT }\end{array}$ & $\begin{array}{l}\text { MPLT(hrs) for } \\
\text { open model }\end{array}$ \\
\hline & & & \\
1 & 34.99 & 34.99 & 67.05 \\
2 & 49.72 & 24.86 & 92.65 \\
3 & 66.47 & 22.15 & 135.655 \\
4 & 74.97 & 18.74 & 164.211 \\
6 & 110.621 & 18.4 & 192.828 \\
\hline
\end{tabular}


time compression. This is because we do not need to add any additional capacity to the system resources, or incur any overheads such as rejecting purchase requisitions. We only choose the way in which to prioritize work corresponding to internal flows or internal processes. In the model, at any given station, we distinguish between work by the history of sojourn in the network and due dates that different jobs are carrying and schedule the jobs depending on what is required to be 0 . In simple terms, we rush jobs that are likely to bring down the mean lead time and slow down the progress of jobs that have much impact on the mean lead time. In the context of e-procurement, the scheduling strategies have implications on how the internal subprocesses of various current procurement activities are scheduled. The attractive aspect of employing these policies arises by virtue of not having to commit any additional resources or personnel for various procurement tasks. We are only prioritizing individual work elements in an appropriate way. A purchasing manager can implement this effectively.

Table 4 shows the effect of operating the eprocurement process in a fixed population mode (that is, there are always a fixed number of purchasing projects in progress at any given point of time) The second column in Table 4 gives the mean cycle time, the third column gives the mean inter-arrival times that are consequent on having the corresponding population in the closed network, the last column gives the mean cycle time if the procurement process is operated as an open network with these throughput rates. Thus lower lead times are achieved for a specified throughput rate (number of purchasing orders it can complete in a given time). A closed mode will entail rejection of some purchasing needs and also continuous availability of fresh purchasing needs for initiation. With proper coordination, sharing of information, and upfront planning between the purchasing department and users, input control of the fixed population type can be implemented.

\section{A. Conclusions}

In this paper, we have exploited the discrete event dynamical nature of the e-procurement process and modeled it using queueing networks. Needless to say, the model presented is stylized and at an aggregate level, and is still not representative of all the details and distinctive aspects of a procurement organization. Only a comprehensive simulation model provides a partial answer to the problem of creating a faithful replica of a given procurement process. What we have attempted and succeeded in doing here is to come up with a good analytical model that captures certain important performance determinants of e-procurement and use the model towards a deeper understanding of lead time management issues. The model captures the effect of various lead time reduction strategies at the level of abstraction of a procurement manager. Such models can be used by managers in aggregate procurement planning and management. In order to use such models in detailed planning, one has to enrich the models and also the analysis techniques. In this sense, the paper certainly throws open several interesting issues for further investigation.

The models described can become the foundation of a software tool that can be used by procurement managers.

\section{REFERENCES}

11] A.Segev, C.Beam, Gebauer, Impact of the Internet on Purchasing Practices Preliminary Results from a Field 0,CMIT Working paper 97-WP-1024, September, 1997.

[2] Gebauer, Faerber, Streamlining Procurement and Engineering at Lawrence Livermore National Laboratory, $A n$ nals of Cases on Information Technology Applications and Management in Organizations, vol.2, 2000.

[3] M.E. Nissen, Procurement Revolution with Intelligent Agent Technology, PRACTIX, December 1999

[4] W.J. Hopp and M.L. Spearman, Factory Physics: Foundations of Manufacturing Management, McGraw-Hill,1996.

[5] P. R. Kumar, Re-Entrant lines, Queueing Systems: Theory and applications, vol.13, pp.87-110, 1993.

[6] S.H. Lu, D.Ramaswamy, and P.R. Kumar, Efficient scheduling policies to reduce mean and variance of cycletime in semiconductor manufacturing plants, IEEE Transactions on Semiconductor Manufacturing, vol. 7, no. 3, pp. 374-388, August 1994.

[7] Center for Advanced Purchasing Studies Research, http://www.capsresearch.org

[8] PunchasingNet, http://www.purchasingnet.com

[9] Y. Narahari, N. Viswanadham, and V. Kiran Kumar, Lead Time Modeling and Acceleration of Product Design and Development, IEEE Transactions On Robotics and Automation, vol.15, no.5, pp.882-896, October 1999.

[10] R. Nelson, D. Towsley, and A. N. Tantawi, Performance analysis of parallel Processing Systems, IEEE Transactions on Software Engineering, vol. 14, No. 4, April 1988

[I1] D. Towsley, G. Rommel, and A. Stankovic, Analysis of forkjoin response times on multiprocessors, IEEE Transactions on Parallel and Distributed Systems, vol.1, 286-303.

[12] Y. Narahari, and P. Sundarrajan, Performability Analysis of Fork-join Queueing Systems, Journal of the Operational Research Society vol.46, 1237-1249. 1995

[13] J.P. Baron, M.J. Shaw, and A.D. Bailey, Jr. Web-based Ecatalog systems in B2B Procurement, Communications of the $A C M$, vol. 43, No. 5, May 2000.

[14] N. Viswanadham and Y. Narahari. Queueing network modeling and lead time compression of pharmaceutical drug development. International Journal of Production Research, vol. 39, no 2, pp. 395-412, 2001.

[15] Steven Kaplan and Mohanbir Sawhney, E-hubs: The New B2B Marketplaces, Harvard Business Review, May-June 2000 